\title{
Quality of Life, Care Resource Use, and Costs of Dementia in 8 European Countries in a Cross- Sectional Cohort of the Actifcare Study
}

Citation for published version (APA):

Handels, R. L. H., Skoldunger, A., Bieber, A., Edwards, R. T., Goncalves-Pereire, M., Hopper, L., Irving, K., Jelley, H., Kerpershoek, L., Marques, M. J., Meyer, G., Michelet, M., Portolani, E., Rosvik, J., Selbaek, G., Stephan, A., de Vugt, M., Wolfs, C., Woods, B., ... ActifCare Consortium (2018). Quality of Life, Care Resource Use, and Costs of Dementia in 8 European Countries in a Cross-Sectional Cohort of the Actifcare Study. Journal of Alzheimer's Disease, 66(3), 1027-1040. https://doi.org/10.3233/JAD-180275

Document status and date:

Published: 01/01/2018

DOI:

10.3233/JAD-180275

Document Version:

Publisher's PDF, also known as Version of record

Document license:

Taverne

Please check the document version of this publication:

- A submitted manuscript is the version of the article upon submission and before peer-review. There can be important differences between the submitted version and the official published version of record.

People interested in the research are advised to contact the author for the final version of the publication, or visit the DOI to the publisher's website.

- The final author version and the galley proof are versions of the publication after peer review.

- The final published version features the final layout of the paper including the volume, issue and page numbers.

Link to publication

\footnotetext{
General rights rights.

- You may freely distribute the URL identifying the publication in the public portal. please follow below link for the End User Agreement:

www.umlib.nl/taverne-license

Take down policy

If you believe that this document breaches copyright please contact us at:

repository@maastrichtuniversity.nl

providing details and we will investigate your claim.
}

Copyright and moral rights for the publications made accessible in the public portal are retained by the authors and/or other copyright owners and it is a condition of accessing publications that users recognise and abide by the legal requirements associated with these

- Users may download and print one copy of any publication from the public portal for the purpose of private study or research.

- You may not further distribute the material or use it for any profit-making activity or commercial gain

If the publication is distributed under the terms of Article $25 \mathrm{fa}$ of the Dutch Copyright Act, indicated by the "Taverne" license above, 


\section{Quality of Life, Care Resource Use, and Costs of Dementia in 8 European Countries in a Cross-Sectional Cohort of the Actifcare Study}

Ron L.H. Handels ${ }^{\mathrm{a}, \mathrm{b}, *}$, Anders Sköldunger ${ }^{\mathrm{b}}$, Anja Bieber $^{\mathrm{e}}$, Rhiannon Tudor Edwards ${ }^{\mathrm{k}}$, Manuel Gonçalves-Pereira ${ }^{\mathrm{c}}$, Louise Hopper ${ }^{\mathrm{d}}$, Kate Irving ${ }^{\mathrm{d}}$, Hannah Jelley ${ }^{\mathrm{i}}$, Liselot Kerpershoek ${ }^{\mathrm{a}}$, Maria J. Marques ${ }^{\mathrm{c}}$, Gabriele Meyer ${ }^{\mathrm{e}}$, Mona Michelet ${ }^{\mathrm{f}, \mathrm{h}, \mathrm{m}}$, Elisa Portolani ${ }^{\mathrm{j}}$, Janne Røsvik ${ }^{\mathrm{f}, \mathrm{m}}$, Geir Selbaek ${ }^{\mathrm{f}, \mathrm{g}, \mathrm{h}}$, Astrid Stephan ${ }^{\mathrm{e}}$, Marjolein de Vugt ${ }^{\mathrm{a}}$, Claire Wolfs ${ }^{\mathrm{a}}$, Bob Woods ${ }^{\mathrm{i}}$, Orazio Zanetti ${ }^{\mathrm{j}}$, Frans Verhey ${ }^{\mathrm{a}}$, Anders Wimo ${ }^{\mathrm{b}, 1}$ and Actifcare consortium

${ }^{a}$ Department of Psychiatry and Neuropsychology, Alzheimer Centre Limburg, School for Mental Health and Neurosciences, Maastricht University, Maastricht, The Netherlands

${ }^{\mathrm{b}}$ Department of Neurobiology, Care Science and Society, Division of Neurogeriatrics, Karolinska Institute, Stockholm, Sweden

${ }^{\mathrm{c}}$ CEDOC, Chronic Diseases Research Centre, NOVA Medical School/Faculdade de Ciências Médicas, Universidade Nova de Lisboa, Portugal

${ }^{\mathrm{d} S c h o o l ~ o f ~ N u r s i n g ~ a n d ~ H u m a n ~ S c i e n c e s, ~ D u b l i n ~ C i t y ~ U n i v e r s i t y, ~ D u b l i n, ~ I r e l a n d ~}$

${ }^{\mathrm{e}}$ Martin Luther University Halle-Wittenberg, Medical Faculty, Institute for Health and Nursing Science, Halle (Saale), Germany

${ }^{\mathrm{f}}$ Norwegian National Advisory Unit on Ageing and Health, Vestfold Health Trust, Tфnsberg, Norway ${ }^{\mathrm{g}}$ Centre for Old Age Psychiatric Research, Innlandet Hospital Trust, Ottestad, Norway

${ }^{\mathrm{h}}$ Faculty of Medicine, Institute of Health and Society, University of Oslo, Oslo, Norway

${ }^{\mathrm{i}}$ Dementia Services Development Centre Wales (DSDC), Bangor University, Bangor, United Kingdom ${ }^{j}$ Alzheimer's Unit - Memory Clinic, IRCCS Centro San Giovanni di Dio Fatebenefratelli, Brescia, Italy

${ }^{\mathrm{k}}$ Centre for Health Economics and Medicines Evaluation, Bangor University, Bangor, United Kingdom ${ }^{1}$ Centre for Research \& Development, Uppsala University/County Council of Gävleborg, Gävle, Sweden ${ }^{\mathrm{m}}$ Department of Geriatric Medicine, Oslo University Hospital, Norway

Handling Associate Editor: Bernhard Michalowsky

Accepted 11 September 2018

\section{Abstract.}

Background: With 10.5 million people with dementia in Europe and $\$ 301$ billion associated costs, governments face challenges organizing access to care.

Objective: To examine the costs related to formal and informal care use and quality of life for people with dementia in eight European countries, and explore the association with unmet needs.

\footnotetext{
*Correspondence to: Ron Handels, Alzheimer Centre Limburg, Maastricht University, P.O. Box 616, 6200 MD Maastricht, The Netherlands. E-mail: ron.handels@maastrichtuniversity.nl.
} 
Methods: Cross-sectional data from 451 persons with dementia and their informal caregivers of the Actifcare cohort study were obtained. Formal and informal care use was multiplied by country specific unit prices of services. Needs were measured using the CANE and health-related quality of life (HRQOL) of the person with dementia (both self- and proxy-rated) and informal caregiver's quality of life using EQ-5D-5L, ICECAP-O, DEMQOL-U, and CarerQol utility scores. The association between costs and country, European region, and unmet needs was assessed using multi-level linear regression.

Results: Self-rated EQ-5D-5L utility score was higher than proxy-rated ( 0.84 and 0.71 , respectively). Informal caregivers' utility score was 0.84 . Across eight countries annual mean costs of formal and informal care were approximately $€ 17,000$. Unmet needs were not associated with annual costs of care, nor with proxy-rated HRQOL, but were associated with self-rated HRQOL.

Conclusion: We found varying relationships between unmet needs and quality of life, and no association between unmet needs and care costs, although the results were sensitive to various factors. Future research should further investigate the relation between unmet needs, quality of life and costs to generate a better understanding of the effects of (un)timely access to care.

Keywords: Access to care, costs, dementia, health-economics, quality of life, unmet needs

\section{INTRODUCTION}

Dementia, caused by Alzheimer's disease (AD) or related diseases, forms a major health, social, and economic global challenge of the 21 st century. This has been highlighted as a priority by the WHO [1] as well as the European Parliament [2]. It is estimated that 10.5 million people in Europe have dementia [3] accounting for over $22 \%$ of the total number of people with dementia worldwide. The total societal costs of dementia in Europe in 2015 were estimated at \$301 billion, of which $\$ 180$ billion were costs of medical and social care and $\$ 121$ billion were related to informal care [3].

In recent decades, various national and international organizations and collaborations such as Alzheimer's Disease International and the ALCOVE project have promoted timely recognition of dementia [4]. One aim of timely recognition is to improve access to services such as home care support that could help to maintain independence and dignity. People with dementia probably could stay at home longer with their families if the right support was put in place that addresses their needs. Most countries acknowledge that this is important and have policies to develop better home-based and community services and reduce institutionalization [5]. Research has revealed that people with dementia and their informal caregivers are not receiving services of the type and quality that they need, and that they experience difficulties accessing and working with community care services, even with a diagnosis of dementia [6,7]. This can put increased pressure on people with dementia and their families which might lead to admission to institutional care because the appropriate support is not in place [8]. Thus, despite the potential benefits of timely access to formal care and the need for these services to support informal caregivers, low rates of service use are still observed. In addition, there is great diversity and inequity among different health care and social care systems related to dementia between and within individual European countries $[5,9,10]$. The right to health care is an essential element of the Universal Declaration of Human Rights [11] and of the UN Convention on the Rights of Persons with Disabilities [12]. It is widely acknowledged that social and economic inequalities in access to health care should be eliminated to meet the needs of elderly [13]. Therefore, there is a need for research-based studies to chart, analyze, and evaluate the strengths and weaknesses of individual pathways to care and infrastructures. The impact of dementia on the population of Europe is of such a magnitude that this problem must be addressed cooperatively across European countries.

Demographic changes and an aging population (and as a consequence, an increasing number of people with dementia) means most countries in Europe are facing great challenges in the current and future long-term funding of care for elderly, and people with dementia in particular. Due to the impact of resource use and costs of dementia on health care and social care systems in Europe, a proper understanding of the costs and outcomes of formal and informal care services utilization is fundamentally important for raising awareness, achieving effective prioritization, and focusing efforts to improve the lives of people with dementia and their caregivers.

The overall aim of this study is to examine the costs related to formal and informal care use and quality 
of life for people with dementia in eight European countries, and explore the association with unmet needs.

\section{METHODS}

\section{Design and participants}

In the Actifcare (ACcess to TImely Formal care) study [14], participants with dementia and their informal caregivers were recruited in 2014 and 2015 in a prospective longitudinal cohort (baseline, 6 months, and 12 months follow-up) in eight European countries: Germany (DE), Ireland (IE), Italy (IT), the Netherlands (NL), Norway (NO), Portugal (PT), Sweden (SE), and United Kingdom (UK). Measurement instrument scores (reflecting sociodemographics, cognition, care use, quality of life, quality of relationship, capability, (un)met needs, neuropsychiatric symptoms, comorbidity, activities of daily life for the people with dementia, and social isolation, quality of relationship, quality of life, anxiety and depression, perseverance time, stress, capability, control, sense of coherence, and personal and social resources for the informal carers) were obtained by a personal interview between the person with dementia, the informal caregiver and the researcher, and part of them were used for this study. In every country ethical approval was obtained separately and written informed consent was attained for both the person with dementia and the caregiver. Eligibility criteria were: 1) Diagnosis of dementia by DSM IV TR; 2) Clinical dementia rating score mild or moderate or Mini-Mental State Examination (MMSE) $\leq 24$; 3) Not receiving regular assistance from a paid worker with personal care on account of his/her dementia; 4) Additional assistance with personal care within 1 year is likely judged by a healthcare professional; 5) An informal caregiver willing to participate; 6) Able to complete the assessments; 7) Not been in care home or nursing home during the previous 6 months; 8) No alcohol-related dementia or Huntington's disease. For this study, cross-sectional data from the baseline assessment has been used.

\section{Clinical measurement instruments and unmet needs}

We measured dementia severity and various domains of symptoms using the following instruments: MMSE [15] to reflect cognitive functioning; the Lawton instrumental activities of daily living scale (IADLS) [16] and the Physical SelfMaintenance Scale (PSMS) [16] to rate activities of daily living; and the Neuropsychiatric Inventory (NPI-Q) [17] to reflect neuropsychiatric symptoms. We used sum scores of these scales in the analysis.

Needs were measured by the Camberwell Assessment of Need for the Elderly scale (CANE) [18] and scored by the researcher taking into account both the perspectives of the person with dementia and the informal caregiver. This interview-based questionnaire has been designed to map the needs (present and, if so, met or unmet) and amount of help (received and needed) for older people over 24 categories covering psychological, physical and environmental domains. A total sum of met needs and a total sum of unmet needs was generated.

\section{Health-related quality of life, wellbeing, and utility}

Quality of life and wellbeing measures relevant for health-economic evaluation included the EQ5D-5L, ICECAP-O, DEMQOL-U, and CarerQol, as they reflect the general health-related, wellbeing covering dimensions 'beyond health', disease specific and caregiver-related quality of life respectively, and enable the calculation of a tariff-based utility score. The EQ-5D-5L, ICECAP-O, and DEMQOL-U of the person with dementia were all self-rated and proxyrated by the informal caregiver.

Index values were available for the EQ-5D-5L (among the participating countries in Actifcare: UK $[19,20]$, NL [21], ongoing for DE and PT [22], and crosswalk set for DE, NL, and UK [23]), the ICECAP-O (UK [24]), the DEMQOL-U and DEMQOL-PROXY-U (UK $[25,26]$ both general population as well as dementia-specific population), and the CarerQol (NL [27]). Due to the lack of index values for the countries included in our Actifcare study, we used the UK index values for each country in our study. In addition, the Visual Analogue Scale (VAS) of the CarerQol and the EQ-5D-5L were used. See notes Table 2 for score ranges and interpretation.

\section{Resource use and costing formal and informal care}

The Resource Utilization in Dementia (RUD) instrument [28] was used to collect data on resource 
use consumed by both the person with dementia and the informal caregiver in terms of frequency and intensity (number of visits or time measured in days, visits or hours) from a societal perspective. This included living accommodation (person with dementia), admission to hospital (both person with dementia and informal caregiver), hospital emergency room (both), care professionals (both), services (nursing, home care, food delivery, day care, transportation and other) (person with dementia), informal care and absenteeism from work / income losses associated with caring for person with dementia (informal caregiver). Resource use was measured over a recall period of 30 days at baseline. The RUD instrument uses estimates of the amount of informal care received in three domains: personal Activities of Daily Living (ADL), instrumental ADL and supervision (i.e., prevent dangerous events). The RUD instrument has been widely used and comprehensively validated [29, 30].

To calculate the resource use related costs, frequencies of resource use were multiplied by unit prices. Prices were based on specific national sources, publications with multi-country price estimates [31, 32], and assumptions based on authors' opinion (see Supplementary Table 1), and transformed to Euros reflecting the year 2015. Costs were linearly extrapolated to a 1-year period to enable comparison with other studies. Informal care was valued according to the opportunity cost of which the hourly rate was reflected by the mean wage derived from http://ec.europa.eu/eurostat for each country in our study. This was only applied to personal ADL and instrumental ADL, which reflect active caring time. To reflect the mix of retired and non-retired informal caregivers $35 \%$ of the country specific mean wage was used [33].

\section{Statistical analysis}

Summary statistics were provided for demographics and outcomes in terms of disease severity, quality of life, resource use, and corresponding costs of the consumed care resources of the person with dementia and their informal caregivers. For resource use, both the percentage users and the mean frequencies of resource use among the users were estimated. Costs were bootstrapped using 5000 replicates and the 2.5 th and 97.5th percentile of the mean was estimated using the statistical software R3.3.1 [34].

Missing demographic, clinical, HRQOL, and care usage were item-wise deleted (e.g., when a participant had missing visits to a neurologist, this participant was omitted for the calculation of mean care professional usage but not for mean accommodation). For the calculation of costs, frequencies of resource use were imputed across the entire dataset by multiple imputation using the STATA13 chained equations and predictive mean matching command to construct an imputation model with age and gender of both the person with dementia and informal caregiver, MMSE, IADLS, PSMS and NPI, CANE, quality of life as well as RUD items as predictor variables. Ten imputed datasets were generated. The mean of all 10 imputed datasets was used only for describing the costs by country and category of number of unmet needs (see below).

Country differences regarding demographics, disease severity and quality of life were assessed using ANOVA and Chi-square tests. A multivariate regression model was used to assess cost differences between countries and country regions (Northern: Norway and Sweden; Western: Germany, Ireland, Netherlands, and United Kingdom; Southern: Italy and Portugal). To ensure the regression assumption of linearity, costs were transformed using the natural log with a data-driven optimal correction factor. These were $\ln (\operatorname{costs}+1087)$ when using country-specific unit prices and $\ln ($ costs +1621$)$ when using mean unit prices. Person with dementia demographic (age and gender) and disease severity (MMSE, IADLS, PSMS, and NPI) variables were included in both models as covariates.

The association between natural log transformed costs and unmet needs was assessed using regression. The number of unmet needs according to the CANE instrument was categorized into 0, 1-2, and more than 2 based on expert opinion (AW, AS, RH). A mixed model was used with country as random factor to adjust for country differences. The number of needs was considered a confounder and was therefore included as a covariate. It was also assumed to reflect the effects of age, comorbidities and functional dependency. Similarly, the association between categorized unmet needs and both self- and proxy-rated EQ-5D-5L was assessed. In all analyses, $p<0.05$ was considered significant.

\section{Sensitivity analysis}

We explored various alternative options in sensitivity analyses. The mean of the country-specific unit prices was used to exclude any differences 
Table 1

Sample demographic and clinical characteristics.

\begin{tabular}{|c|c|c|c|c|c|c|c|c|c|}
\hline & $\begin{array}{l}\text { Norway } \\
(n=60)\end{array}$ & $\begin{array}{l}\text { Sweden } \\
(n=50)\end{array}$ & $\begin{array}{l}\text { Germany } \\
(n=54)\end{array}$ & $\begin{array}{l}\text { Ireland } \\
(n=43)\end{array}$ & $\begin{array}{l}\text { Netherlands } \\
\quad(n=51)\end{array}$ & $\begin{array}{c}\text { United } \\
\text { Kingdom } \\
(n=76)\end{array}$ & $\begin{array}{c}\text { Italy } \\
(n=53)\end{array}$ & $\begin{array}{l}\text { Portugal } \\
(n=66)\end{array}$ & $\begin{array}{c}\text { All } \\
(n=451)\end{array}$ \\
\hline & North & North & West & West & West & West & South & South & \\
\hline \multicolumn{10}{|l|}{ Person with dementia } \\
\hline Age* & $78(7)$ & $80(7)$ & $77(9)$ & $74(9)$ & $76(8)$ & $79(8)$ & $79(8)$ & 77 (6) & $78(8)$ \\
\hline Female gender* & $60 \%$ & $52 \%$ & $42 \%$ & $51 \%$ & $57 \%$ & $43 \%$ & $70 \%$ & $62 \%$ & $55 \%$ \\
\hline Education (years)* & $11(3)$ & $9(3)$ & $12(3)$ & $12(4)$ & $11(4)$ & $11(2)$ & $7(4)$ & $6(6)$ & $10(4)$ \\
\hline \multicolumn{10}{|l|}{ Marital status } \\
\hline Married & $70 \%$ & $72 \%$ & $73 \%$ & $67 \%$ & $78 \%$ & $48 \%$ & $58 \%$ & $76 \%$ & $69 \%$ \\
\hline Widowed & $20 \%$ & $21 \%$ & $21 \%$ & $28 \%$ & $16 \%$ & $34 \%$ & $40 \%$ & $18 \%$ & $24 \%$ \\
\hline Other & $10 \%$ & $7 \%$ & $6 \%$ & $5 \%$ & $6 \%$ & $18 \%$ & $2 \%$ & $6 \%$ & $7 \%$ \\
\hline Lives in own home* & $95 \%$ & $99 \%$ & $98 \%$ & $100 \%$ & $94 \%$ & $100 \%$ & $91 \%$ & $82 \%$ & $94 \%$ \\
\hline Lives together with carer* & $73 \%$ & $82 \%$ & $77 \%$ & $58 \%$ & $80 \%$ & $52 \%$ & $55 \%$ & $85 \%$ & $72 \%$ \\
\hline \multicolumn{10}{|c|}{ Clinical characteristics person with dementia } \\
\hline $\operatorname{MMSE}(0-30)^{*}$ & $19.1(4.9)$ & $20.4(4.4)$ & $20.2(5.9)$ & $20.3(5.4)$ & $19.8(4.3)$ & $18.8(5.4)$ & $16.9(3.7)$ & $17.8(4.8)$ & $19.0(5.0)$ \\
\hline $\operatorname{IADLS}(0-8)^{*}$ & $4.2(1.8)$ & $3.0(2.0)$ & $3.3(2.0)$ & $3.4(2.6)$ & $3.9(1.7)$ & $3.0(1.7)$ & $3.0(1.8)$ & $3.7(2.0)$ & $3.4(2.0)$ \\
\hline $\operatorname{PSMS}(0-6)^{*}$ & $4.5(1.3)$ & $4.0(1.8)$ & $3.2(2.1)$ & $3.4(2.0)$ & $4.1(1.8)$ & $3.4(1.8)$ & $2.8(1.8)$ & $3.7(2.0)$ & $3.6(1.9)$ \\
\hline NPI $(0-30)^{*}$ & $8.8(5.1)$ & $5.6(4.4)$ & $6.1(4.7)$ & $8.9(5.5)$ & $9.1(6.5)$ & $7.9(5.5)$ & $8.7(5.8)$ & $6.8(5.5)$ & $7.7(5.5)$ \\
\hline CANE met needs $(0-24)^{*}$ & $8.6(2.3)$ & $4.5(2.1)$ & $10.0(4.5)$ & $8.3(3.6)$ & $7.2(2.5)$ & $9.2(3.4)$ & $9.0(2.0)$ & $8.2(2.8)$ & $8.2(3.3)$ \\
\hline CANE unmet needs $(0-24)^{*}$ & $2.2(1.5)$ & $0.1(0.6)$ & $1.4(2.0)$ & $3.3(2.3)$ & $2.6(2.5)$ & $1.7(1.7)$ & $1.7(1.9)$ & $1.2(1.7)$ & $1.8(2.0)$ \\
\hline \multicolumn{10}{|l|}{ Informal caregiver } \\
\hline Age* $^{*}$ & $70(13)$ & $67(12)$ & $69(12)$ & $58(15)$ & $69(9)$ & $70(10)$ & $60(13)$ & $65(15)$ & $66(13)$ \\
\hline Female gender & $58 \%$ & $58 \%$ & $73 \%$ & $77 \%$ & $55 \%$ & $72 \%$ & $72 \%$ & $67 \%$ & $67 \%$ \\
\hline Education (years)* & $12(4)$ & $11(3)$ & $14(4)$ & $15(4)$ & $12(3)$ & $12(3)$ & $11(4)$ & $9(6)$ & $12(4)$ \\
\hline \multicolumn{10}{|l|}{ Marital status* } \\
\hline Single/widowed & $8 \%$ & $8 \%$ & $10 \%$ & $16 \%$ & $10 \%$ & $14 \%$ & $15 \%$ & $14 \%$ & $12 \%$ \\
\hline Married/partnership/co-habiting & $92 \%$ & $92 \%$ & $88 \%$ & $84 \%$ & $90 \%$ & $86 \%$ & $85 \%$ & $86 \%$ & $88 \%$ \\
\hline \multicolumn{10}{|l|}{ Relation to person with dementia* } \\
\hline Spouse/partner & $73 \%$ & $76 \%$ & $75 \%$ & $53 \%$ & $75 \%$ & $52 \%$ & $38 \%$ & $61 \%$ & $64 \%$ \\
\hline Son/daughter (in law) & $25 \%$ & $22 \%$ & $21 \%$ & $42 \%$ & $20 \%$ & $40 \%$ & $57 \%$ & $35 \%$ & $32 \%$ \\
\hline Other & $2 \%$ & $1 \%$ & $4 \%$ & $5 \%$ & $6 \%$ & $8 \%$ & $6 \%$ & $5 \%$ & $4 \%$ \\
\hline
\end{tabular}

CANE, Camberwell Assessment of Need for the Elderly; IADLS, instrumental activities of daily living scale; MMSE, Mini-Mental State Examination; NPI, neuropsychiatric inventory; PSMS, Physical Self-Maintenance scale. The range (best possible score underlined) of the MMSE is 0 to $\underline{30}$, IADLS 0 to $\underline{8}$, PSMS 0 to $\underline{6}$, NPI $\underline{0}$ to 30 , CANE met needs 0 to $\underline{24}$, and CANE unmet needs $\underline{0}$ to 24 . ${ }^{*} p$-value $<0.05$ for overall country-differences.

between countries in how the unit price was build-up. In two other options, the price from the country with the lowest (Italy) and highest (Norway) mean price was applied to all countries. For informal care on personal ADL and instrumental ADL, a proxy good cost unit price was used reflecting the mean wage for a person in the social care sector (also known as the replacement cost approach). Furthermore, the costs of informal care supervision were included in an option by applying the same unit prices as for personal ADL and instrumental ADL. Two imputation options of case-wise deletion and imputation with 0 were applied on resource use.

The regression analyses on costs were alternatively run using mean unit prices instead of country-specific unit prices. As an alternative to categorizing the number of unmet needs, it was included in the analysis as a continuous measure in both the costs and HRQOL analyses.

\section{RESULTS}

In total 451 people with dementia and their informal caregivers (dyads) participated in the Actifcare study and were eligible for these analyses. The mean age of people with dementia was 78 (SD: 8) and $55 \%$ were female (see Table 1). Almost all (94\%) lived at home and a few in non-dementia-specific intermediate forms of accommodation, with a large proportion living with their informal caregiver (72\%). Their mean MMSE was 19.0 (SD: 5.0) reflecting a cognitive deficit in the mild to moderate dementia range. The mean age of informal caregivers was 66 (SD: 13) and they were mainly spouses/partners $(64 \%)$ or sons/daughters $(32 \%)$ of the person with dementia. All demographic characteristics differed significantly between countries, except for the gender of the informal caregiver (see Table 1). The missing data for each of the scales was less than $8 \%$ (see Supplementary Table 2). 


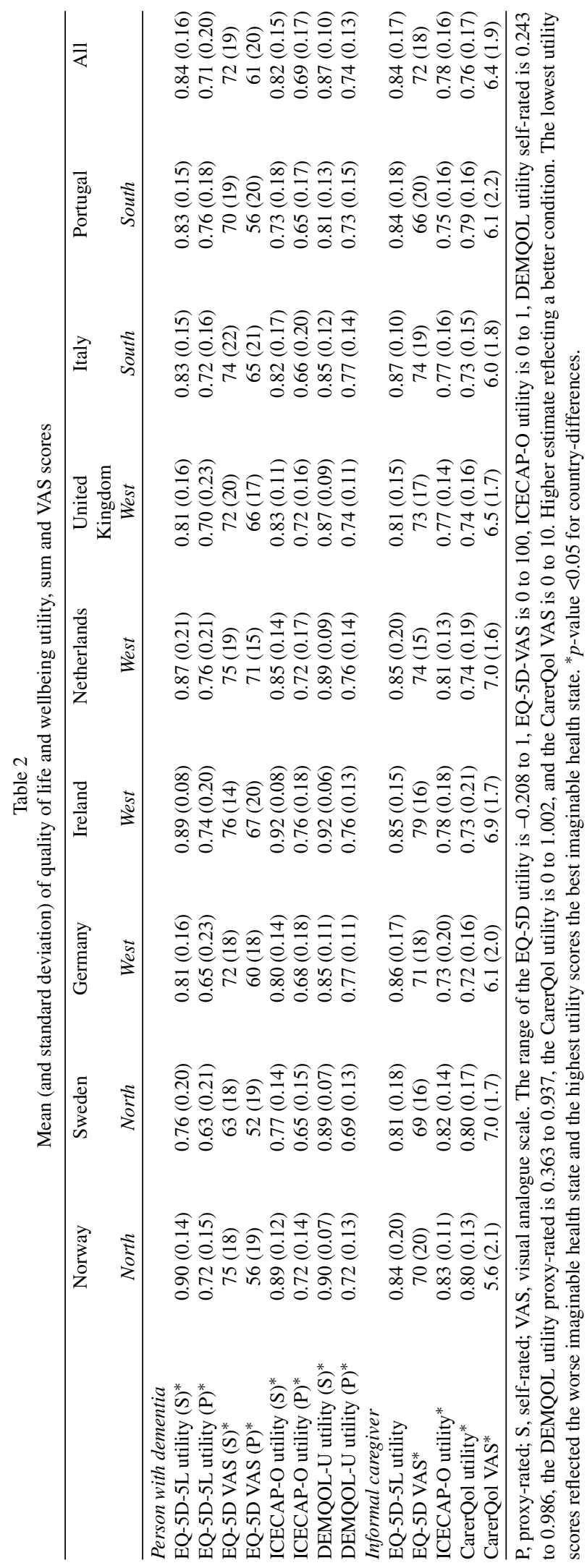


Table 3

Mean (and standard deviation or 2.5 and 97.5 percentile bootstrap interval) of demographic, quality of life and costs by unmet needs (societal costs in Euro (2015) of 30-day resource use prior to the baseline assessment up scaled to 1-year; imputed data)

\begin{tabular}{|c|c|c|c|c|}
\hline & $\begin{array}{c}\text { No unmet } \\
\text { needs }(n=156)\end{array}$ & $\begin{array}{c}1 \text { or } 2 \text { unmet } \\
\text { needs }(n=162)\end{array}$ & $\begin{array}{c}3 \text { or more unmet } \\
\text { unmet needs }(n=133)\end{array}$ & All \\
\hline \multicolumn{5}{|l|}{ Person with dementia } \\
\hline Age & $78(7)$ & $77(8)$ & $78(9)$ & $78(8)$ \\
\hline Female gender & $52 \%$ & $59 \%$ & $53 \%$ & $55 \%$ \\
\hline Lives together with caregiver & $72 \%$ & $73 \%$ & $70 \%$ & $72 \%$ \\
\hline \multicolumn{5}{|c|}{ Clinical characteristics person with dementia } \\
\hline MMSE (0-30) & $19.3(4.8)$ & $18.4(5.2)$ & $19.1(5.1)$ & $18.9(5.1)$ \\
\hline IADLS $(0-8)$ & $3.5(2.0)$ & $3.6(2.0)$ & $3.2(2.0)$ & $3.4(2.0)$ \\
\hline PSMS $(0-6)$ & $3.8(1.9)$ & $3.8(1.8)$ & $3.4(2.0)$ & $3.7(1.9)$ \\
\hline NPI $(0-30)$ & $5.7(4.4)$ & $7.8(5.4)$ & $10.1(6.0)$ & $7.8(5.6)$ \\
\hline CANE met needs (0-24) & $7.7(3.8)$ & $8.8(2.9)$ & $7.7(2.9)$ & $8.1(3.3)$ \\
\hline CANE unmet needs (0-24) & $0.0(0.0)$ & $1.4(0.5)$ & $4.5(1.9)$ & $1.8(2.1)$ \\
\hline \multicolumn{5}{|l|}{ Informal caregiver } \\
\hline Age & $68(13)$ & $66(13)$ & $66(14)$ & $66(13)$ \\
\hline Female gender & $66 \%$ & $67 \%$ & $67 \%$ & $67 \%$ \\
\hline \multicolumn{5}{|l|}{ Person with dementia } \\
\hline EQ-5D-5L utility (S)* & $0.83(0.16)$ & $0.88(0.13)$ & $0.81(0.19)$ & $0.84(0.16)$ \\
\hline EQ-5D-5L utility $(\mathrm{P})^{*}$ & $0.72(0.20)$ & $0.75(0.19)$ & $0.68(0.20)$ & $0.72(0.20)$ \\
\hline EQ-5D VAS (S) & $72(18)$ & $74(19)$ & $71(20)$ & $72(19)$ \\
\hline EQ-5D VAS (P) & $62(19)$ & $63(20)$ & $58(20)$ & $61(20)$ \\
\hline ICECAP-O utility (S)* & $0.83(0.12)$ & $0.86(0.14)$ & $0.79(0.18)$ & $0.83(0.15)$ \\
\hline ICECAP-O utility $(\mathrm{P})^{*}$ & $0.71(0.17)$ & $0.72(0.15)$ & $0.65(0.18)$ & $0.69(0.17)$ \\
\hline DEMQOL-U utility $(\mathrm{S})^{*}$ & $0.89(0.07)$ & $0.88(0.09)$ & $0.85(0.13)$ & $0.87(0.10)$ \\
\hline DEMQOL-U utility (P) & $0.75(0.13)$ & $0.74(0.13)$ & $0.72(0.13)$ & $0.74(0.13)$ \\
\hline \multicolumn{5}{|l|}{ Informal caregiver } \\
\hline EQ-5D-5L utility & $0.84(0.15)$ & $0.85(0.18)$ & $0.82(0.18)$ & $0.84(0.17)$ \\
\hline EQ-5D VAS & $72(17)$ & $73(19)$ & $70(19)$ & $72(18)$ \\
\hline ICECAP-O utility* & $0.79(0.15)$ & $0.80(0.14)$ & $0.76(0.17)$ & $0.78(0.16)$ \\
\hline CarerQol utility* & $0.79(0.15)$ & $0.77(0.17)$ & $0.72(0.17)$ & $0.76(0.17)$ \\
\hline \multicolumn{5}{|l|}{ Person with dementia } \\
\hline Accommodation ${ }^{1}$ & $0(0-0)$ & $146(97-199)$ & $1,241(870-1640)$ & 417 (304-539) \\
\hline Hospital admission and emergency & $1,129(862-1417)$ & $550(379-737)$ & $2,948(1660-4360)$ & $1,456(1078-1900)$ \\
\hline Care professional $^{2}$ & $1,432(1354-1515)$ & $992(936-1047)$ & $991(920-1062)$ & $1,144(1104-1186)$ \\
\hline Services $^{3}$ & $2,585(2187-3011)$ & $2,195(1876-2556)$ & $1,315(1137-1501)$ & $2,071(1873-2262)$ \\
\hline \multicolumn{5}{|l|}{ Informal caregiver } \\
\hline Informal care & $8,604(8156-9073)$ & 9,425 (8996-9879) & $10,636(10092-11171)$ & 9,497 (9227-9769) \\
\hline Hospital admission and emergency & $737(330-1225)$ & $552(340-818)$ & $1,929(1001-2980)$ & $1,021(694-1377)$ \\
\hline Care professionals ${ }^{2}$ & $676(617-738)$ & $700(634-766)$ & $1,007(913-1111)$ & $782(739-828)$ \\
\hline Productivity losses & $1,142(803-1506)$ & $536(389-706)$ & $1,083(844-1342)$ & $907(755-1065)$ \\
\hline Total & $16,305(15383-17314)$ & $15,095(14426-15750)$ & $21,151(19477-23030)$ & $17,296(16634-18004)$ \\
\hline
\end{tabular}

P, proxy-rated; S, self-rated; VAS, visual analogue scale.

The utility ranges are 0-1, EQ-5D-VAS is 0-100 and the CarerQol VAS is 0-10, with higher estimate reflecting a better condition.

*p-value $<0.05$.

${ }^{1}$ Accommodation response options included accommodation in own home, intermediate, dementia specific, long-term institutional, and other (see Supplementary Table 3).

${ }^{2}$ Professional response options included general practitioner, geriatrician, neurologist, psychiatrist, physiotherapist, occupational therapist, social worker, psychologist, and other.

${ }^{3}$ Services response options included district nurse, home aid, food delivery, day care, transportation, and other (see Supplementary Table 3).

Mean quality of life and wellbeing scores are presented in Table 2. The mean health-related quality of life of the people with dementia was 0.84 (self-rated) and 0.71 (proxy-rated). A higher self-rated score was also observed for the EQ-5D VAS (72 versus 61), wellbeing measured by the ICECAP-O $(0.82$ versus 0.69 on a $0-1$ scale), and DEMQOL-U (0.87 versus 0.74). Paired $t$-tests found significant differences for all self- and proxy ratings. Informal caregivers on average scored their own health-related quality of life 0.84, wellbeing 0.78, and CarerQol 0.76. All except the informal caregiver's EQ-5D-5L utility score significantly differed between countries. Person with dementia self-reported quality of life (excluding EQ5D VAS) significantly differed by reported unmet need; those having 3 or more unmet needs reported 


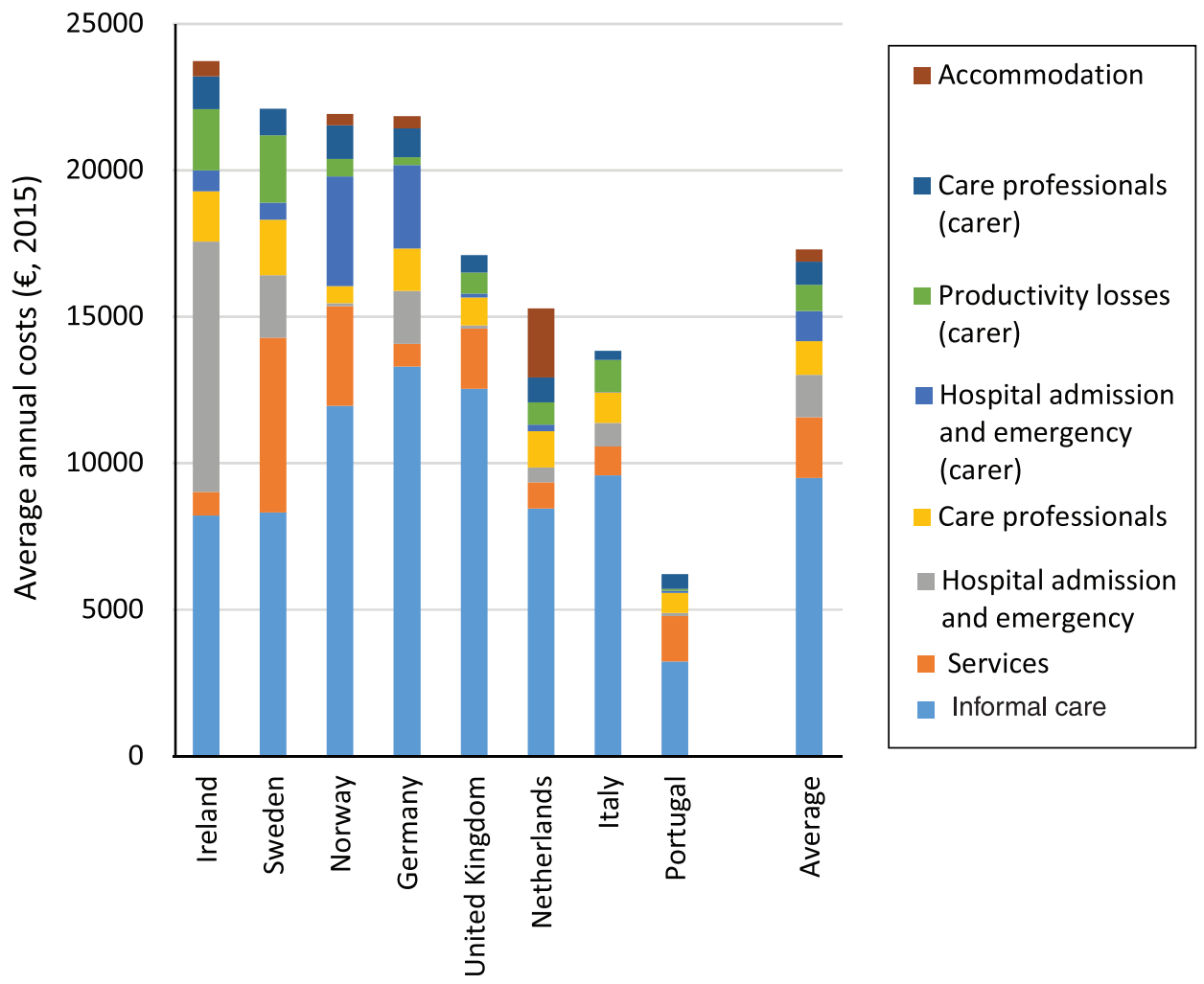

Fig. 1. Mean annual societal costs in Euro (2015).

significantly lower quality of life. These differences were, however, small (see Table 3). There was a similar pattern for the proxy ratings and the carer self-report, although fewer of the differences were significant.

Extrapolated annual mean costs related to resource use were $€ 17,296$ across countries. About half of these costs were related to informal care $(€ 9,497)$. Highest total costs occurred in Ireland $(€ 23,737)$ and lowest in Portugal $(€ 6,222)$ (see Fig. 1 and Table 4). Costs relating to accommodation were highest in the Netherlands, and Ireland had the highest costs for hospital admission and emergency for participants. Portugal had low informal care costs, which was mainly related to the low unit price as resource use was near the mean usage in the whole sample across eight countries. Supplementary Table 3 provides an overview of the mean reported resources used in the 30 days before the baseline assessment.

Transformed costs significantly differed between countries $(p<0.001)$ as well as between country regions $(p<0.001)$ after correcting for participants' demographic and disease severity characteristics.

Categorized unmet needs (see Table 3) were not significantly associated with transformed costs $(p=0.180)$, were also not significantly related to the proxy-rated EQ-5D-5L utility score of the person with dementia $(p=0.426)$, but were significantly related to the self-rated EQ-5D-5L $(p=0.009)$.

\section{Sensitivity analysis}

Sensitivity analysis showed a variation in mean total cost of service use (formal and informal care) when relying on different assumptions regarding unit prices, cost categories and handling missing data (see Supplementary Table 4). Although mean total cost of service use between countries varied, the impact of using mean of all country unit prices instead of country-specific unit prices was relatively small. The value assigned to informal care had a large impact on mean total cost of formal and informal care. The imputation method case-wise deletion affected the mean total costs of Germany. This can be explained by the fact that a large proportion of the German participants had one or only a few missing responses to one of the various items of the care use questionnaire, requiring the case-wise deleting of these participants from this particular scenario of the sensitivity analysis (opposite to a relatively small proportion of 


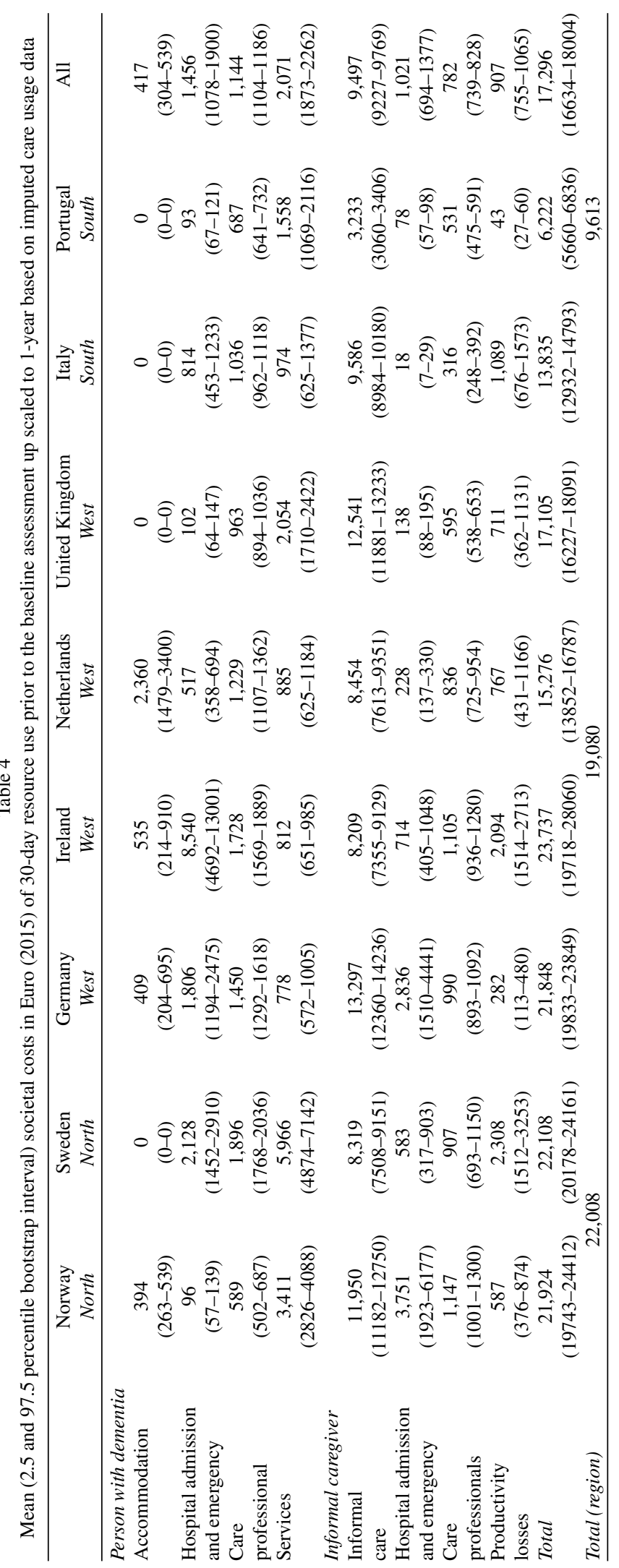


participants with missing responses in the other country samples) (see Supplementary Table 2).

Country differences in costs were also significant when relying on mean unit prices $(p=0.021)$ but country region differences were not $(p=0.603)$.

Regarding unmet needs, they were significant when relying on mean unit prices $(p=0.028)$. Unmet needs included on a continuous scale were not significant when relying on country-specific unit prices ( $p=0.053$ ) but were when relying on mean unit prices $(p=0.014)$. Unmet needs on a continuous scale were not significantly related both to proxy- $(p<0.129)$ or self-rated $(p<0.072)$ quality of life. Residuals in the analyses were good (costs) to moderately (quality of life) normally distributed.

\section{DISCUSSION}

\section{Summary of findings}

The annual mean costs in eight countries in Northern, Western, and Southern European were $€ 17,296$ in a convenience sample of people with dementia and their informal caregivers, but it differed between countries. The main cost driver was informal care (55\% of the total costs). Persons with dementia rated their health-related quality of life higher than their proxies. Unmet needs were not associated to transformed costs or health-related quality of life rated by the informal caregivers of the people with dementia.

The costs differed between countries in terms of the amount of care provided, its economic value reflected by the unit price and its corresponding costs. Although the included countries in this study reflect European welfare state systems, there are nevertheless differences in how care is organized and financed. The costs and outcomes that are presented seem to reflect the expected differences in terms of high consumption of formal care in Northern and Western Europe, but not in terms of informal care. Compared to all countries, mean usage, Portugal and Italy had slightly lower and slightly higher informal care use respectively. In Portugal, this could be explained by the low unit price as well as the reported use of the services of a "housekeeper" (mean 17.9 hours in 30 days), which may have substituted or prevented informal care in this sample. Some differences between the division of care over the various care sectors might be due to outliers, as for example in Ireland one person reported all days of the recall period spent in a hospital corresponding to an impact of $€ 6,667$ on the mean total costs in Ireland ( $€ 530$ on the mean total costs of all countries; this is on the border of the 2.5 and 97.5 percentile bootstrap interval). The case was not excluded since it was a justified observation and was therefore explored in the sensitivity analyses. Also, unobserved demographic or disease severity characteristics that are associated to costs or HRQOL could have differed between the country-specific samples, which could have biased the country differences.

Mean annual care costs of AD-type dementia were estimated $€ 6,063$ in Northern Europe, $€ 8,279$ in Western Europe, and $€ 7,049$ in Southern Europe in the ICTUS study [35]. Our estimates were higher and could mainly be explained by the exclusion of medical care consumption by the informal caregiver, the difference in population due to recently diagnosed patients at a memory clinic (with a large proportion of very mild $\mathrm{AD}$ ), and the lower unit price applied to informal care in the ICTUS study. Similar to the ICTUS study, we observed lower medical care in Southern Europe, but we did not observe higher informal care for the possible reasons explained earlier. The total annual costs in a subsample of mild and moderate AD-type dementia in the GERAS study [36] were $€ 20,376$ in three Western European countries. This was similar to our findings as well as the proportion of costs in the costs categories in the overlapping countries Germany and United Kingdom. The sample characteristics in terms of demographics and disease severity also were similar, as well as the unit prices and included costs components. However, specific to this study were two of the inclusion criteria (exclusion of persons receiving regular paid assistance; including persons who will likely receive formal personal care within 1 year), of which the first could have resulted in a lower estimate and the second in a higher estimate of care use compared to the typical studied secondary memory clinic population with a recent diagnosis of AD-type dementia.

Compared with Parkinson's disease, our sample reflects a relatively large proportion of costs related to non-medical costs (informal care and social services) and a relatively small proportion of direct medical costs, which has been more equally distributed in Parkinson's disease [37-39].

The proxy-rated person with dementia's quality of life was lower than the person with dementia's selfrating (with somewhat higher proportions of missing data for the self-rated observations, see Supplementary Table 2). This has been shown earlier [40] and highlights the issue of the rater's perspective. People with mild and moderate dementia can to a great extent express their views. However, as the disease 
progresses, awareness of memory and functional limitations decreases [41]. Awareness was also found to be associated with sociodemographic characteristics and the relation between the person with dementia and the informal caregiver [42]. If a person with dementia rates aspects of quality of life as "good or high level" (domains of quality of life may include cognitive but also functional aspects) but a proxy has a different perspective and therefore rates them as "worse or low level", one could wonder which perspective (patient, proxy or presenting both) best fits the research question of a particular study. Various studies have indicated differences between both perspectives [43], which suggested further research is needed.

Costs could not be explained by the number of unmet needs in the main analysis, for which various explanations are plausible. Costs were based on care usage in the 30-day period before the observation of unmet needs. Although a relatively short time period, care use could have affected needs. Also, the use of medical and informal care could not have been a consequence of the unmet needs (e.g., care related to crisis situations because a lack of supervision or day care activities). The association also seemed to be dependent on the unit price, as the sensitivity analyses indicated a significant association when relying on mean unit prices. The analysis was, however, subject to limited power since at baseline of the Actifcare study persons using dementia-related formal care were excluded from participation, leaving limited possibilities to observe so-called dementiarelated consequential care. The impact of unmet needs on service use would be expected to emerge in longitudinal analyses, especially in situations where informal care is not successful in meeting the unmet need. HRQOL was also not related to unmet needs, although these results were dependent on who rated the HRQOL (sensitive to proxy- versus self-rating). Also, it unexpectedly increased from 0 to 1 or 2 unmet needs $(+0.03)$ and decreased from 1 or 2 to 3 or more $(-0.07)$. Subgroup differences in terms of demographics and the particular needs that are unmet could be confounding factors in this association, or there could be a tipping point where unmet needs begin to impact on HRQOL.

\section{Limitations}

For the regression analysis on costs predicted by unmet needs, the care-related costs were observed earlier in time than the unmet needs. The care use in this period could have affected the needs. However, given the relative short time period of 30 days and our expectation that care use and needs are relatively stable over this time period, we did not expect this to have a significant impact on the results.

This analysis was based on a specific sample of home-dwelling persons with mild or moderate dementia. The people with dementia in this study were living at home at baseline and were selected based on their probability of needing formal care within 1 year. They do not represent the general population with dementia and thus it is not possible to generalize our results to reflect the cost of illness of the national dementia population in each country. The representativeness was further limited by the relatively small country-specific sample sizes (ranging from 43 to 76), which made them prone to coincidental effects on the inclusion. The descriptive statistics were not adjusted for possible country differences and should therefore be interpreted with caution. Also, the imputation procedure did not adjust for country differences. Although alternative imputation strategies have been explored and did not result in relevant differences in costs, it could have had an impact on the results. Countries in Eastern Europe were not included in the Actifcare project. These countries can be expected to differ from the other regions.

Costs related to medication use were not included and therefore the total care costs are underestimated. However, these costs were likely to be small as they reflected less than $10 \%$ of the total costs in the ICTUS study [35]. The costs due to productivity loss were partly double-counted with the costs related to hours providing informal care, which slightly overestimated the total costs. Although rescaling costs observed over a 30-day period to 1 year does not affect the significance in the regression analysis, these might not reflect the actual 1-year costs.

The economic valuing of informal care is a complicated and controversial topic [44]. A standard is completely lacking and thus transparency regarding how informal care is quantified and valued is crucial, as is varying uncertainties in a sensitivity analysis.

Country-specific prices were likely subject to methodological differences. Among them was a difference in how the price was built up (e.g., hotel costs in- or excluded in hospital care price). The location at which prices are published varied and the language was often non-English, which increased the likelihood of missing important sources. Some sources reported a price per hospital or care home admission without clear information on the mean days of 
an admission, making it difficult to transform it into the format of the RUD questionnaire. There were also discrepancies between the designation or description of the care type by the RUD questionnaire and by the source reporting the unit price (e.g., prices reported for diagnosis-related-groups), as well as differences in the year at which a price was derived (see Supplementary Tables 1 and 5 for details). These limitations strongly indicate the need to harmonize the methods to calculate care unit prices in Europe and make them easily accessible (such as aimed by the PECUNIA project, http://www.pecunia-project.eu).

Some of the uncertainties due to the limitations were taken into account in the sensitivity analysis to reflect their impact on the total costs and results of the analyses. In explorative post-hoc analyses, the cut-off for low and high numbers of unmet needs was ranged between 1 and 10 but did not result in any significant relation between categorized unmet needs and care costs. However, various results were significant for $p<0.20$ and omitting participants with high number of unmet needs (more than 10) resulted in a significant relation between unmet needs and costs as well as when included on a continuous scale, indicating this relation was sensitive to the method and unstable, and therewith subject for future research. The posthoc analysis and sensitivity analysis were subject to multiple testing for which was not adjusted. They should be considered as explorative results.

\section{Recommendations for future research}

The sensitivity of the associations between unmet needs and costs, and unmet needs and HRQOL to the unit prices, rater and outcome scale indicates there might be a potential for efforts on improving the access to care to improve the quality of life for people with dementia and reduce their costs. However, further research into this topic is crucial to explore subgroups with a strong association between unmet needs and costs or unmet needs and HRQOL (potentially a combination of the living situation and presence of behavioral or cognitive symptoms). Such knowledge could help to develop person-tailored interventions that can be applied to a subgroup with a high potential for improving their HRQOL.

In addition, longitudinal data is important to reflect upon the timing of care (longer enduring unmet needs might have a larger impact on care use and HRQOL) and the type of need (unmet need on neuropsychiatric symptoms might weigh heavier on for example informal caregiver time and HRQOL than an unmet need on compliance to medication). Furthermore, details on the degree of unmet needs and the proportion of a need already being met by informal care could be used to increase our understanding of the effects of unmet needs on costs and HRQOL. The potential effect is large as mean annual costs have been estimated to be $€ 29,148$ and $€ 53,892$ in a population consuming professional home care and institutional long-term nursing respectively [45], which is significantly higher than the costs estimated in our population of persons not consuming professional care. These topics, however, fell outside the scope of this analysis and are topic of research within the Actifcare study [14].

\section{Conclusion}

Our eight country European study, one of the largest comparative studies in dementia care, did not find a relationship between unmet needs and quality of life, and not between unmet needs and care costs, although the results were sensitive to various factors. Given the interaction between formal and informal care future research should unravel the relationship between unmet needs, quality of life and costs to generate a better understanding of the effects of (un)timely access to care.

\section{ACKNOWLEDGMENTS}

This is an EU Joint Programme - Neurodegenerative Disease Research (JPND) project. The project is supported through the following funding organisations under the aegis of JPND - http://www.jpnd.eu (Germany, Bundesministerium für Bildung und Forschung (BMBF), Ireland, Health Research Board (HRB), Italy, Italian Ministry of Health, Netherlands, The Netherlands Organization for Health Research and Development (ZonMW)/ Alzheimer Netherlands, Norway, The Research Council of Norway, Portugal, Fundação para a Ciência e a Tecnologia (FCT-JPND-HC/0001/2012), Sweden, Swedish Research Council (SRC), United Kingdom, Economic and Social Research Council (ESRC)).

Authors' disclosures available online (https:// www.j-alz.com/manuscript-disclosures/18-0275r3).

\section{SUPPLEMENTARY MATERIAL}

The supplementary material is available in the electronic version of this article: http://dx.doi.org/ 10.3233/JAD-180275. 


\section{REFERENCES}

[1] WHO (2012) Dementia: A public health priority. World Health Organization \& Alzheimer Disease International, Geneva. Retrieved from http://apps.who.int/iris/bit stream/10665/75263/1/9789241564458_eng.pdf, Accessed on March 26, 2018.

[2] European Parliament resolution of 19 January 2011 on a European initiative on Alzheimer's disease and other dementias (2010/2084(INI)). Strassbourg: 2011. Retrieved from http://www.europarl.europa.eu/sides/getDoc.do?type=TA\& reference $=$ P7-TA-2011-0016\&language $=\mathrm{EN}$, Accessed on March 26, 2018.

[3] Prince M, Wimo A, Guerchet M, Ali G, WU Y, Prina M (2015) World Alzheimer Report 2015: The Global Impact of Dementia. Alzheimer's Disease International, London. Retrieved from https://www.alz.co.uk/research/worldreport-2015, Accessed on March 26, 2018.

[4] Brooker D, Fontaine J La, Evans S, Bray J, Saad K (2014) Public health guidance to facilitate timely diagnosis of dementia: ALzheimer's COoperative Valuation in Europe recommendations. Int J Geriatr Psychiatry 29, 682-693.

[5] Knapp M, Comas-Herrera A, Banerjee S (2007) Dementia. International comparisons. Summary report for the National Audit Office. Personal Social Services Research Unit, School of Economics and Political Science and the Institute of Psychiatry, King's College, London. Retrieved from https://www.pssru.ac.uk/pub/dp2418.pdf, Accessed on March 26, 2018.

[6] Brodaty H, Thomson C, Thompson C, Fine M (2005) Why caregivers of people with dementia and memory loss don't use services. Int J Geriatr Psychiatry 20, 537-546.

[7] Wolfs CAG, de Vugt ME, Verkaaik M, Haufe M, Verkade PJ, Verhey FRJ, Stevens F (2012) Rational decision-making about treatment and care in dementia: A contradiction in terms? Patient Educ Couns 87, 43-48.

[8] Gordis L (2009) Epidemiology, Saunders Elsevier, Philadelphia.

[9] Alzheimer Europe (2017) European Dementia Monitor 2017. Retrieved from http://alzheimer-europe.org/ Publications/E-Shop/European-Dementia-Monitor-2017/

European-Dementia-Monitor-2017, Accessed on March 26, 2018.

[10] Van Eenoo L, Declercq A, Onder G, Finne-Soveri H, GarmsHomolová V, Jónsson PV, Dix OHM, Smit JH, van Hout HPJ, van der Roest HG (2016) Substantial between-country differences in organising community care for older people in Europe-a review. Eur J Public Health 26, 213-219.

[11] Universal Declaration of Human Rights: Resolution / adopted by the General Assembly, in Resolution 217 A. United Nations. 1948. Retrieved from http://www.undocuments.net/a3r217a.htm, Accessed on March 26, 2018.

[12] Convention on the Rights of Persons with Disabilities in $\mathrm{A} / \mathrm{RES} / 61 / 106$. United nations General Assembly. 2007. Retrieved from http://www.un.org/en/development/ desa/population/migration/generalassembly/docs/ globalcompact/A_RES_61_106.pdf, Accessed on March 26, 2018.

[13] Albanese E, Liu Z, Acosta D, Guerra M, Huang Y, Jacob KS, Jimenez-Velazquez IZ, Llibre Rodriguez JJ, Salas A, Sosa AL, Uwakwe R, Williams JD, Borges G, Jotheeswaran AT, Klibanski MG, McCrone P, Ferri CP, Prince MJ (2011) Equity in the delivery of community healthcare to older people: Findings from 10/66 Dementia Research Group cross-sectional surveys in Latin America, China, India and Nigeria. BMC Health Serv Res 11, 153.

[14] Kerpershoek L, de Vugt M, Wolfs C, Jelley H, Orrell M, Woods B, Stephan A, Bieber A, Meyer G, Engedal K, Selbaek G, Handels R, Wimo A, Irving K, Hopper L, Marques M, Gonçalves-Pereira M, Portolani E, Zanetti O, Verhey F (2016) Access to timely formal dementia care in Europe: Protocol of the Actifcare (ACcess to Timely Formal Care) study. BMC Health Serv Res 16, 423.

[15] Folstein MF, Folstein SE, McHugh PR (1975) "Mini-mental state". A practical method for grading the cognitive state of patients for the clinician. J Psychiatr Res 12, 189-198.

[16] Lawton MP, Brody EM (1969) Assessment of older people: Self-maintaining and instrumental activities of daily living. Gerontologist 9, 179-186.

[17] Cummings JL, Mega M, Gray K, Rosenberg-Thompson S, Carusi DA, Gornbein J (1994) The Neuropsychiatric Inventory: Comprehensive assessment of psychopathology in dementia. Neurology 44, 2308-2314.

[18] Reynolds T, Thornicroft G, Abas M, Woods B, Hoe J, Leese M, Orrell M (2000) Camberwell Assessment of Need for the Elderly (CANE). Development, validity and reliability. $\mathrm{Br}$ J Psychiatry 176, 444-452.

[19] Devlin N, Shah K, Feng Y, Mulhern B, van Hout B (2016) Valuing Health-Related Quality of Life: An EQ-5D-5L Value Set for England. Office of Health Economics, London.

[20] Feng Y, Devlin N, Shah K, Mulhern B, van Hout B (2016) New Methods for Modelling EQ-5D-5L Value Sets: An Application to English Data. Office of Health Economics, London.

[21] Versteegh M, Vermeulen K, Evers S, de Wit GA, Prenger R, Stolk E (2016) Dutch tariff for the five-level version of EQ-5D. Value Health 19, 343-352.

[22] EuroQol. EQ5D. Retrieved from https://euroqol. org/research/ (accessed February 22, 2018).

[23] van Hout B, Janssen MF, Feng Y-S, Kohlmann T, Busschbach J, Golicki D, Lloyd A, Scalone L, Kind P, Pickard AS (2012) Interim Scoring for the EQ-5D-5L: Mapping the EQ-5D-5L to EQ-5D-3L Value Sets. Value Health 15, 708-715.

[24] Coast J, Flynn TN, Natarajan L, Sproston K, Lewis J, Louviere JJ, Peters TJ (2008) Valuing the ICECAP capability index for older people. Soc Sci Med 67, 874-882.

[25] Mulhern B, Rowen D, Brazier J, Smith S, Romeo R, Tait R, Watchurst C, Chua K-C, Loftus V, Young T, Lamping D, Knapp M, Howard R, Banerjee S (2013) Development of DEMQOL-U and DEMQOL-PROXY-U: Generation of preference-based indices from DEMQOL and DEMQOLPROXY for use in economic evaluation. Health Technol Assess 17, v-Xv, 1-140.

[26] Rowen D, Mulhern B, Banerjee S, van Hout B, Young TA, Knapp M, Smith SC, Lamping DL, Brazier JE (2012) Estimating preference-based single index measures for dementia using DEMQOL and DEMQOL-proxy. Value Health 15, 346-356.

[27] Hoefman RJ, van Exel J, Rose JM, van de Wetering EJ, Brouwer WBF (2014) A discrete choice experiment to obtain a tariff for valuing informal care situations measured with the CarerQol instrument. Med Decis Making 34, 84-96.

[28] Wimo A, Gustavsson A, Jönsson L, Winblad B, Hsu M-A, Gannon B (2013) Application of Resource Utilization in Dementia (RUD) instrument in a global setting. Alzheimers Dement 9, 429-435.e17. 
[29] Wimo A, Jonsson L, Zbrozek A (2010) The Resource Utilization in Dementia (RUD) instrument is valid for assessing informal care time in community-living patients with dementia. $J$ Nutr Health Aging 14, 685-690.

[30] Wimo A, Nordberg G (2007) Validity and reliability of assessments of time. Arch Gerontol Geriatr 44, 71-81.

[31] Reed C, Happich M, Argimon JM, Haro JM, Wimo A, Bruno G, Dodel R, Jones RW, Vellas B, Belger M (2017) What drives country differences in cost of Alzheimer's disease? An explanation from resource use in the GERAS Study. $J$ Alzheimers Dis 57, 797-812.

[32] Luengo-Fernandez R, Leal J, Gray AM (2011) Cost of dementia in the pre-enlargement countries of the european union. J Alzheimers Dis 27, 187-196.

[33] Johannesson M, Borgquist L, Jönsson B, Råstam L (1991) The costs of treating hypertension-an analysis of different cut-off points. Health Policy 18, 141-150.

[34] R Core Team (2016) R: A language and environment for statistical computing. R Foundation for Statistical Computing, Vienna, Austria. URL https://www.R-project.org/.

[35] Gustavsson A, Jonsson L, Rapp T, Reynish E, Ousset PJ, Andrieu S, Cantet C, Winblad B, Vellas B, Wimo A (2010) Differences in resource use and costs of dementia care between European countries: Baseline data from the ICTUS study. J Nutr Health Aging 14, 648-654.

[36] Wimo A, Reed CC, Dodel R, Belger M, Jones RW, Happich M, Argimon JM, Bruno G, Novick D, Vellas B, Haro JM (2013) The GERAS study: A prospective observational study of costs and resource use in community dwellers with Alzheimer's disease in three European countries - Study design and baseline findings. J Alzheimers Dis 36, 385-399.

[37] Gustavsson A, Svensson M, Jacobi F, Allgulander C, Alonso J, Beghi E, Dodel R, Ekman M, Faravelli C, Fratiglioni L, Gannon B, Jones DH, Jennum P, Jordanova A, Jönsson L, Karampampa K, Knapp M, Kobelt G, Kurth T, Lieb R, Linde M, Ljungcrantz C, Maercker A, Melin B, Moscarelli M, Musayev A, Norwood F, Preisig M, Pugliatti M, Rehm J, Salvador-Carulla L, Schlehofer B, Simon R, Steinhausen H-C, Stovner LJ, Vallat J-M, den Bergh P Van, van Os J, Vos P, Xu W, Wittchen H-U, Jönsson B, Olesen J, Olesen
J, CDBE2010Study Group (2011) Cost of disorders of the brain in Europe 2010. Eur Neuropsychopharmacol 21, 718 779.

[38] von Campenhausen S, Winter Y, Rodrigues e Silva A, Sampaio C, Ruzicka E, Barone P, Poewe W, Guekht A, Mateus C, Pfeiffer K-P, Berger K, Skoupa J, Bötzel K, Geiger-Gritsch S, Siebert U, Balzer-Geldsetzer M, Oertel WH, Dodel R, Reese JP (2011) Costs of illness and care in Parkinson's Disease: An evaluation in six countries. Eur Neuropsychopharmacol 21, 180-191.

[39] Rodríguez-Blázquez C, Forjaz MJ, Lizán L, Paz S, Martínez-Martín P (2015) Estimating the direct and indirect costs associated with Parkinson's disease. Expert Rev Pharmacoecon Outcomes Res 15, 889-911.

[40] Jönsson L, Andreasen N, Kilander L, Soininen H, Waldemar G, Nygaard H, Winblad B, Jönhagen ME, Hallikainen M, Wimo A (2006) Patient- and proxy-reported utility in Alzheimer disease using the EuroQoL. Alzheimer Dis Assoc Disord 20, 49-55.

[41] Wilson RS, Sytsma J, Barnes LL, Boyle PA (2016) Anosognosia in dementia. Curr Neurol Neurosci Rep 16, 77.

[42] Clare L, Nelis SM, Martyr A, Roberts J, Whitaker CJ, Markova IS, Roth I, Woods RT, Morris RG (2012) The influence of psychological, social and contextual factors on the expression and measurement of awareness in early-stage dementia: Testing a biopsychosocial model. Int J Geriatr Psychiatry 27, 167-177.

[43] Hounsome N, Orrell M, Edwards RT (2011) EQ-5D as a quality of life measure in people with dementia and their carers: Evidence and key issues. Value Health 14, 390-399.

[44] Koopmanschap MA, van Exel JNA, van den Berg B, Brouwer WBF (2008) An overview of methods and applications to value informal care in economic evaluations of healthcare. Pharmacoeconomics 26, 269-280.

[45] Wübker A, Zwakhalen SMG, Challis D, Suhonen R, Karlsson S, Zabalegui A, Soto M, Saks K, Sauerland D (2015) Costs of care for people with dementia just before and after nursing home placement: Primary data from eight European countries. Eur J Health Econ 16, 689-707. 